\title{
Understanding elementary school teachers of mathematics
}

\author{
Olive Chapman ${ }^{1}$
}

Published online: 20 April 2017

(C) Springer Science+Business Media Dordrecht 2017

Elementary school teachers of mathematics are instrumental to students' development of meaningful and effective ways of learning, doing, and thinking about mathematics to support their future success in mathematics and mathematics-related disciplines in higher grades and beyond. Thus, research on the mathematics teacher continues to focus more on elementary school teachers in a variety of ways, with emphasis on their learning, mathematics and pedagogical mathematical knowledge, and beliefs. Some researchers continue to focus on deficiency-oriented studies that highlight what these teachers do not know and what should be fixed in teacher education or professional development programs. This deficit-based way of understanding and educating mathematics teachers is potentially more damaging than helpful to the teachers. It tends to dehumanize the teacher and embody simplistic views of knowledge, the teaching/learning process and their interrelationship. Studies need to transcend the deficit approach and recognize the importance of understanding the teacher's personal knowledge, thinking, and experiences regarding mathematics in ways that will provide a meaningful basis of their learning and growth in teaching mathematics. Such studies focus on understanding teachers from their perspectives; for example, in terms of their learning, their instructional approaches, and what they know and can do. This way of understanding elementary school teachers of mathematics is important to address the complexities and support autonomy in their learning of how to effectively engage their students in meaningful learning of mathematics and to create innovative learning environments in their mathematics classrooms.

This issue of the Journal of Mathematics Teacher Education consists of four articles that address prospective elementary school teachers, a practising elementary school teacher, and a teacher educator and teacher coaches of elementary school teachers. They offer different ways of understanding these teachers in the context of learning to teach, teaching, or supporting the teaching of elementary school mathematics. Rong-Ji Chen's article focuses on prospective teachers' dispositions toward mathematics; Charles Hohensee's

Olive Chapman

chapman@ucalgary.ca

1 University of Calgary, Calgary, Canada 
article considers prospective teachers' learning of early algebra; Rukiye Didem Taylan's article reports on a practising teachers' noticing of students' thinking; and Margret Hjalmarson's article attends to her role as course designer and teacher regarding a course for teacher coaches. The articles attend to the teachers' perspectives to varying degrees as highlighted in the following summaries.

Chen examined prospective teachers' relationships to mathematics, focusing on how they saw themselves as learners of mathematics, their relationships to mathematics and the degree to which they found aesthetic value and personal meaning in mathematics. Participants were six prospective teachers in two credential programs for prospective elementary school teachers in the USA. Analysis of the interview and written reflection data resulted in the following three themes, consisting of cognitive, affective, and esthetic dimensions, of their views on themselves as learners of mathematics: (1) Participants developed different levels of obligations (i.e., obligations-to-others-doing mathematics according to other people's agendas or just to cooperate with the teacher, and obligationsto-oneself-deriving personal meanings in learning mathematics) and autonomy, which were related to how they positioned themselves as learners of mathematics. (2) Participants had an instrumental relationship with mathematics and regarded mathematics as an objective, external world. (3) Four participants viewed themselves as learners of mathematics in relation to aesthetic experience.

Hohensee investigated the insights and challenges that prospective elementary school teachers experienced when exploring pre-symbolic, early algebraic reasoning in a semester-long content course that focused on generalized arithmetic, functional relationships and the relational interpretation of the equal sign. The 13 participants were enrolled in a content course for prospective elementary school teachers at a University in the USA. They had taken algebra in high school but did not remember having experiences in their own elementary education that involved pre-symbolic algebraic reasoning. Twenty of the 28 lessons that comprised the course focused on early algebra. Data collected in conjunction with a course assignment involved participants working in groups of twos and threes on three early algebra tasks that mirrored the themes of the course. Results showed that the participants experienced meaningful new insights regarding distinguishing between the operational and the relational interpretation of the equal sign and representing unknown and variable quantities in informal ways that do not involve algebraic symbols. However, they continued to experience conceptual challenges in conceiving algebra from a functional perspective and engaging in pre-symbolic algebraic reasoning. Hohensee viewed these challenges as aspects of their developing understanding on which they had not yet made sufficient progress.

Taylan investigated the characteristics of a third-grade teacher's noticing of student mathematical thinking in the moment of teaching. Noticing was conceptualized as both attending to different elements of classroom instruction and making sense of classroom events. The participant was a "highly accomplished teacher" who taught grade 3 for six years and had three years of experience attending a contextualized and intensive professional development program in Turkey. Data sources consisted of video records of mathematics classes involving the concepts of multiplication and division, student work, field notes, and videotaped interviews. Findings indicated that the teacher paid the most attention to student thinking and attended to classroom norms, such as engaging students in providing respectful and mathematical feedback to peers, working well within partnerships, and admitting and learning from mistakes. These norms supported the goal of establishing a classroom environment in which students were encouraged to share their 
thinking. The results also indicated how the teacher's noticing might influence her instructional decisions.

Hjalmarson conducted a self-study to examine what guided her design decisions in facilitating learning in an online, project-based course for mathematics-teacher coaches. The course, within a master's degree program in the USA, included weekly videoconferencing sessions and focused on supporting the participants' development as mathematics coaches working with K-8 teachers to improve their mathematics teaching and learning. The course consisted of the following two major projects: (1) a lesson study where the course participants worked in groups to plan, design, implement and reflect on a lesson, and (2) a coaching cycle with a teacher in which the course participants worked individually and videotaped or audiotaped their planning and debriefing sessions with the teacher. The study focused on two sections of the course, with 11 students in one section and 21 students in the other. Data sources were reflective journals and survey. Findings consisted of three themes regarding the instructor's role as course designer and teacher: supporting engagement and autonomy, creating authentic and practical learning experiences, and fostering collaboration and community. These themes guided her choices as well as helped her to understand how her students could interact with the content and each other in the course in the online setting.

These four studies contribute to our understanding of the different categories of elementary school teachers of mathematics and a teacher educator based on their thinking, learning, and teaching. They draw attention to the possible nature of teachers' disposition toward mathematics, learning of early algebra concepts, noticing during teaching, and designing of an online education course. Each article also addresses implications for teacher education. For example, Chen suggests a need to engage teachers in reflection on the nature of mathematics and what it means to do mathematics. Hohensee suggests that an exploration of pre-symbolic algebraic reasoning that involves the three mathematical themes addressed in the early algebra lessons (i.e., generalized arithmetic, functional relationships, and the relational interpretation of the equal sign) can be a non-trivial experience for prospective teachers and likely necessary to adequately prepare them to teach early algebra. Taylan suggests that a teacher's noticing of student thinking during a complex teaching environment can shape her instructional decisions and actions and help to support student learning more meaningfully. Hjalmarson suggests that the themes of autonomy and engagement, authenticity and practicality, and fostering community and collaboration can provide guidance for an instructor about issues and tensions that come to the forefront in an online setting.

The articles imply that we need ongoing research on teachers' dispositions toward mathematics; more research to guide teacher education programs on how to prepare prospective elementary school teachers to teach early algebra; ongoing investigation of teachers' noticing of student thinking during their teaching and how this noticing may shape teaching practices; and further investigation of ongoing creation of online communities of practice. Such research will help to deepen our understanding of elementary school teachers of mathematics and how to meaningfully support their learning of, and growth in, reform-based teaching of mathematics. 